\title{
How do small firms use ICT for business purposes? A study of Swedish technology-based firms
}

\section{Vinit Parida*, Mats Westerberg and Håkan Ylinenpää}

Division of Entrepreneurship and Industrial Organization, Luleå University of Technology, SE-971-87, Sweden

Fax: +46-920-492160

E-mail: vinit.parida@ltu.se

E-mail: mats.westerberg@ltu.se

E-mail: hakan.ylinenpaa@ltu.se

${ }^{*}$ Corresponding author

\begin{abstract}
This study examines the extent to which Information and Communication Technology (ICT) capability is possessed and utilised by technology-based small firms and investigates the contingent effect of firm size and age on ICT capability. The empirical base is a survey with data from 291 technology-based small Swedish firms. The result suggests that technology-based small firms are high users of ICT in several areas. Regarding contingency effects, firm size was related to significant differences in the utilisation of ICT. Although the smallest firms as a whole use ICT less, a substantial part of them are high users.
\end{abstract}

Keywords: ICT; information and communication technology; information technology; capability; firm size; firm age; small firms; resource-based view; Sweden.

Reference to this paper should be made as follows: Parida, V., Westerberg, M. and Ylinenpää, H. (2009) 'How do small firms use ICT for business purposes? A study of Swedish technology-based firms', Int. J. Electronic Business, Vol. 7, No. 5, pp.536-551.

Biographical notes: Vinit Parida is currently pursuing his $\mathrm{PhD}$ in the Division of Entrepreneurship and Industrial Organization at Luleå University of Technology, Sweden. He completed his Technology Licentiate (February 2008) on the topic of Small firms capabilities for competitiveness. His research interest is focused on the capabilities-based view, entrepreneurial orientation, and innovation. He is particularly interested in small and large firms' ability to use inter-firm relationships (networking capability), external knowledge (absorptive capability) and Information and Communication Technology (ICT capability). Recently he has also started working on the topic of 'open innovation'. He has to his credit several scientific publications related to the above-mentioned topics.

Mats Westerberg is an Assistant Professor of Entrepreneurship and Industrial Organization at Luleå University of Technology. He has published his research in several academic journals and in scientific anthologies. His current research interests are in management and entrepreneurship issues in SMEs with special focus on the CEO's role for success and how the network around the firm influences the firm. He runs a small business along with his wife. 
Håkan Ylinenpää is a Professor (Chair) in Entrepreneurship and Head of the Division of Entrepreneurship and Industrial Organisation at Luleå University of Technology, Sweden. His research interests are in entrepreneurial innovation activities and strategies, especially in small and medium-sized enterprises, innovation system research, knowledge management and, preferably, involves research in close collaboration with practise and/or policy-makers in regional, national or international programmes and projects. His has to his credit numerous scientific journal articles, books/book chapters, and conference papers.

\section{Introduction}

Technology-based small firms are considered to play a significant role in the European economy. Delmar et al. (2003) identified seven growth patterns (clusters) in Swedish industries where the highest growth-oriented firms were Small and Medium Size Enterprises (SMEs) operating in knowledge-intensive industries such as the high-technology sector. Thus, technology-based small firms can be considered as most important with regard to job creation and economic growth (Johansson, 2004).

In the face of globalisation, several of these firms are operating in turbulent environments and struggle to remain competitive (Johannessen et al., 1999). Adopting a resource-based view of competitiveness (Barney, 1991), small firms' source of competitiveness may be dependent on the presence of Valuable, Rare, Inimitable, and Non-Substitutable (VRIN) resources and capabilities. In this context, Information and Communication Technology (ICT) capability are of special interest (Hultman and Eriksson, 2008). Previous studies have shown that ICT capability is closely related to innovation and performance (Bharadwaj, 2000; Porter, 2001; Powell and Dent-Micallef, 1997; Ravichandran and Lertwongsatien, 2005). Small firms with a high ICT capability can overcome their 'limitation of smallness' and level the playing field between themselves and larger firms. This insight has driven numerous governmental initiatives around Europe to promote the use of ICT (Matlay and Addis, 2003; Taylor and Murphy, 2004) in, especially, smaller companies. If, and to what degree, small firms actually utilise ICT for business purposes is, however, still poorly studied.

In this study, ICT capability is broadly viewed as a firm's ability to use a wide array of technology, ranging from database programs to local area networks (Martin and Matlay, 2001). Specifically, ICT capability is defined as a firm's ability to use strategically ICT functions or applications for their business purposes and competitive advantage (Johannessen et al., 1999). Thus, the focus lies on using ICT, not merely possessing ICT tools. In previous research, the development of ICT capabilities has normally been related to investments in a firm's ICT infrastructure. Such an approach, however, involves the risk of incomplete and misleading outcomes as the investment per se does not necessarily correspond to the actual use of ICT or the possession of a specific ICT capability (Mata et al., 1995; Porter, 2001). Moreover, only a limited number of studies have explored the aspects of ICT capability and utilisation, and the existing studies are mostly conceptual (Jarvenpaa and Leidner, 1998). Additionally, studies in this area are quickly outdated due to rapid change in the economics of using 
ICT (Caldeira and Ward, 2003). Therefore, there is a significant need to address this specific area of research by addressing small firms' ICT utilisation and capability.

A firm's demographic characteristics such as age and size can also have an impact on the level of ICT capability (Quayle, 2003). It has been argued that younger firms might be more open towards adopting and employing ICT. Regarding size, micro firms (fewer than ten employees) might lack the competence and need for having high usages of ICT. On the other hand, it is especially these micro firms that are expected to benefit most from a high degree of ICT utilisation since this enables these firms to overcome their liability of smallness.

Based on the above arguments, the main purpose of this study is twofold: first, to understand and examine the extent to which ICT capability is possessed and utilised by technology-based small firms and, second, to investigate whether firm size or age influences the extent of ICT capability. This can be further divided into three research questions.

- RQ1: What level of ICT capability is currently possessed by technology-based small firms?

- RQ2: For what business purposes is ICT capability being used by technology-based small firms?

- RQ3: Are there differences regarding the extent to which technology-based small firms possess ICT capability based on firm size and firm age?

This paper will make contributions to the SME-related literature on electronic business (Martin and Matlay, 2001; Taylor and Murphy, 2004). As we will investigate the different usages of ICT for business purposes, this study can shed some light on the usage of ICT in a specific category of small firms. We would also like to advance the literature on ICT capability (Bharadwaj, 2000) by identifying different dimensions that might have been previously overlooked. The structure of this paper is as follows. After the introduction, the theoretical background will be presented. This will be followed by illustrative and explorative case studies. The fourth section will explain the methodological choices made during the study, such as research strategy, data collection, and measurements. Next, we will present the main results obtained from the data analysis. Finally, the paper will conclude with a discussion of the main findings, conclusions, and some implications for theory and practice.

\section{ICT capabilities studies in the literature}

This section will provide insights from a theoretical point of departure into how ICT can be beneficial for small firms' business purposes. These insights combined with data from three explorative case studies will serve as a base for identifying different usages (dimensions) of ICT capability.

ICT capability is here defined as a firm's ability to strategically use ICT functions or applications for their business purposes (Johannessen et al., 1999). A high degree of ICT capability has been shown to influence business processes positively and reduce the cost of production for small firms (Levy et al., 2001). By utilising ICT, firms are able to improve their document handling and use financial and accounting applications that further help them to achieve internal efficiency (Acar et al., 2005). The importance of 
using ICT for strategic planning has also been emphasised in the ICT literature. ICT improves a firm's ability to plan better for the future by providing the CEO or management with easy access to relevant information about different activities and/or operations within and outside the firm (Porter, 2001). The possibility of utilising ICT, e.g., to perform environmental scanning, keep an eye on competitors, and check for new ideas, can facilitate a firm's ability to take calculated risks that can translate into successful strategic plans (Fillis et al., 2003). As the flow of external information increases, the role of employees as part of a firm's absorptive capacity (Cohen and Levinthal, 1990) becomes more significant. When small firms use ICT, the individual employee's capacity to learn is, according to Ruiz-Mercader et al. (2006), increased by generating knowledge through high speed, memory extension, and communication facilities related to technology. This increase in the individual employee's knowledge is likely to significantly impact organisational learning which, in turn, is likely to affect the firm's performance positively.

An essential use of ICT relates to maintaining and establishing collaboration with business partners. Electronic Data Interchange (EDI) networks and other electronic information systems provide a stable connection with trading partners that fosters knowledge sharing and better customer/supplier information exchange (Zaheer and Venkatraman, 1994). Firms with strong ICT capabilities are able to provide special services to their partners, such as updating records of transitions, just-in-time delivery, higher quality communication, etc. All these services can lead to the development of trust, satisfaction, and commitment, which are all important ingredients for healthy relations (Venkatraman, 1994). The investment required for accomplishing such integration is fairly small and may offer small firms a much-needed advantage. Having a high level of ICT usage can create visibility and the recognition of small firms as attractive business partners. This would not only advance their current business, but also secure their chances of collaborating with other attractive partners in the future. Furthermore, ICT makes small firms less limited due to their size and increases their opportunities for doing business and collaborating internationally (Nieto and Fernandez, 2006).

Small firms can also use product data management, virtual prototyping, computer-aided design, and other applications to enhance and speed up the product innovation process (Thomke et al., 1998). Firms with a strong ICT orientation can setup intranet and extranet facilities, which are technological platforms for communication within and outside the firm (suppliers, customers, or partners). This can also provide a constant inflow and outflow of information, which may result in better learning opportunities (Venkatraman, 1994). According to Clemons and Row (1991), information technology can provide a competitive advantage for firms by reducing their structural differences, such as the degree of vertical integration and diversification. Furthermore, small firms can also use their websites as important tools for marketing and market communication. The reach of a website is global and this makes it possible for firms to provide all the basic information about their business at minimum cost (Fillis et al., 2003).

As indicated in the introduction, the level of ICT use may be related to the relative size of the small firm. For the smallest firms, a more sophisticated use of ICT may be difficult to achieve. Especially, regarding uses linked to internal purposes, earlier studies focusing on the formalisation of the firm (e.g., Flamholtz and Randle, 2000; Greiner, 1972) have indicated that firms with fewer than ten employees seldom invest in, 
and use, ICT in their firms due to the fact that communication needs can be solved informally. Once the firm has grown beyond ten employees, the need to formalise the work becomes evident and therefore the use of ICT is likely to be higher (Flamholtz and Randle, 2000; Greiner, 1972). Regarding firm age, the use of ICT is likely to be the highest in firms that are neither too young nor too old. Younger firms are likely to have a scarcity of resources before the company is established on the market, while older firms tend to be 'stale in the saddle', i.e., more rigid and less open to new modes of communication and collaboration (cf. Miller, 1991).

\section{Input from the three explorative case studies}

In order to create a more concrete and relevant base for further studies, three technology-based Swedish small firms were interviewed to provide inputs for developing the ICT capability construct. This explorative approach was deemed appropriate to overcome the already noted fact that the economics of using ICT change very quickly (Caldeira and Ward, 2003). Furthermore, similar approaches have been suggested and adopted and suggested by authors who focused on understanding specific phenomena related to technology within SMEs (Caldeira and Ward, 2003; Southern and Tilley, 2000; Wade et al., 2004). The three companies involved in the pre-study were all located in the city of Lulea in the northern part of Sweden. All three companies deal with ICT solutions in one way or another, but still have their own unique business model. Either the owner-manager or the equivalent with responsibility for ICT was interviewed. The interviewees were asked to explain in detail how they used ICT for their business purpose.

The case-study companies were UniMob $\mathrm{AB}$, isMobile $\mathrm{AB}$, and BnearIT $\mathrm{AB}$. All three companies highlighted the increased importance of ICT for business purposes. E-mails had become a common practice within the firms. All the firms had functional websites but for UniMob this was mainly used for providing general information whereas isMobile and BnearIT provided extra services to their customers through their websites, for example, login possibilities to gain access to information and other facilities. UniMob and isMobile used extensive video conferencing and voice over ISP solutions to interact with distantly located partners. Additionally, UniMob used ICT to find competent individuals for different projects. The respondent at UniMob pointed out that as the firm was quite small (four employees), they had to rely on external collaboration to complete project requirements. This was done by using online blogs, where recruitments were posted and candidates with appropriate knowledge hired for a particular period. Using these blogs, they gained access to a large network of competent people. UniMob, hence, stated that it is important for small firms to use this kind of practice, because appropriate solutions to all problems are not always found within the organisation. Similarly, BnearIT had registered its firm on a portal (e-marketplace) in Sweden in order to have regular information regarding new projects and business opportunities. This helped it in finding potential projects with less hassle and within a smaller time frame. 
Both internal and external communication were largely driven by ICT. Two firms had well-established intranet and extranet setups. The company isMobile, to achieve a smooth flow of information with their main partner (IBM-Europe), had set up a technological platform for communication with a similar standard to their partner. ICT was regarded as 'the life blood' of this relation. Being situated in a small town in the north of Sweden (Luleå) and interacting with a global company like IBM-Europe, it somehow had to compensate for the distance, and ICT was the only appropriate solution to this problem. It also used technology extensively within its own organisation to organise the information flow, buy products online, and for banking practices. BnearIT identified the importance of ICT for communication but also stressed the need for competent employees to maintain the communication. The respondent also explained that firms that have been doing business and that have a good name in the industry have an easier task conducting business through the internet because customers know about them. Thus, the use of information technology may be related to the goodwill or reputation of the small firm.

All the firms agreed on the ease of working from different locations due to ICT facilities. UniMob, for example, had some employees located in Spain. UniMob was also actively involved in outsourcing its projects, where trust was identified as critical to such interaction and collaboration. Overall, it can be seen that each of these firms had different outlooks towards ICT. BnearIT (which is the largest firm in this context with 20 employees and was established in 2002) believed mainly in the use of ICT for internal efficiency and for communication. isMobile (five employees; established in 2000) had a more open attitude towards ICT and claimed that it would not have been able to sustain its business with IBM without utilising ICT facilities. UniMob, finally, which was the smallest and youngest (established 2004) company, relied heavily on ICT to cope with the competition from other small and large firms. It also applied innovative ways to use external collaborations to fill in-house competence gaps.

To conclude, the three illustrative and explorative case studies (Parida and Westerberg, 2006) provide us with some relevant input for addressing this study's research questions, and (together with the theoretical framework outlined in Section 2) serve as an important base for the next phase of this research project - a survey-based investigation into high-tech firms.

\section{Methodology}

This study uses explorative case studies carried out in the autumn of 2006 as one point of departure. These firms conformed to the Swedish industry index (SNI) code 72220 representing consultancy-related computer systems or computer software firms. They were dealing with ICT products or services. When we searched on this code on a Swedish business database (Affärsdata), we found approximately 9000 active firms, and after constraining the targeted population to be fewer than 50 employees (i.e., small firms according to the EU definition) and more than one million Swedish kronor (approximately 100,000 Euro) in sales (to ensure an active firm), we ended up with 3907 active firms. This was considered as the total population. From this population of 3907 firms, 1471 firms were selected for the study (see Table 1). 
Table 1 Five groups based on number of employees

\begin{tabular}{ll}
\hline 1 Employee & 885 Firms \\
2 Employees & 983 Firms \\
$3-5$ Employees & 473 Firms \\
$6-9$ Employees & 698 Firms \\
$10-49$ Employees & 698 Firms \\
\hline
\end{tabular}

Even though the smallest companies (in terms of employees) are interesting to study, it was not deemed appropriate that they should be sampled in relation to their actual numbers (that is a random sample over the whole population) since this would have implicated that the vast majority of firms studied would be (small) micro firms. Therefore, a random sample of 100 was drawn from the first three categories, while the entire population was chosen for the latter two. This means that our study will reflect the 6-49 employee firms to a higher degree than if we had drawn a random sample from the entire population of small firms.

The questionnaires were sent in three sets, between May and July 2007. Each questionnaire was accompanied by a covering letter that was addressed to the Chief Executive Officer (CEO) of the firm, explaining the motivation for this study. As the unit of analysis was at firm level and to obtain a holistic view about firms' ICT operations, it was deemed most appropriate to send the questionnaire to the CEO. A total of 291 usable replies (i.e., $21 \%$ response rate) were received. A non-response analysis was performed by comparing different variables such as firm age (year of establishment), size (number of employees), profit and solidity (i.e., the degree of internally funded capital). The analysis showed no significant differences between respondents and non-respondents. To enhance construct validity and in order to be cumulative with previous studies, an extensive literature review was carried out prior to the operationalisation of the ICT capability construct. In addition, to enhance external validity, the different usages of ICT capability were checked for any problems or irregularities and were pre-tested on CEOs of small firms in a similar industry. The period of pre-testing lasted for almost one month (March 2007). Any doubts, misunderstandings or queries were noted and the questionnaire was modified. This modified version was further tested on new respondents. This process was continued until no major changes were required.

ICT capability measurement was mainly based on the study of Johannessen et al. (1999). Although comprehensive in nature, the measurements were further tested based on the inputs from the three explorative case studies presented in Section 3 (Parida and Westerberg, 2006). This resulted in the identification of 13 different forms of ICT utilisation which together explained the ICT capability (see Table 2). The respondents were asked to mark on a seven point Likert scale from 'not at all' - 'to a large extent', the extent to which they used ICT for the different activities. We believe that these different forms of ICT utilisation will guide us in mapping the extent to which technology-based small firms possess ICT capability. 
Firm age was calculated by subtracting the year of establishment from the year (2007) the survey was conducted. This was further used for forming three groups: young age firms (0-5 years), middle-aged firms (6-10 years), and old firms (11 years and more). Firm size was measured based on the number of employees. This was further divided into two groups according to the European Commission's definitions: micro firms (1-9 employees) and small firms (10-50 employees).

We carried out our analysis using software package SPSS 15.0 version. Initially, we performed descriptive analysis for finding the mean value. Factor analysis was used to find different groups within the 13 dimensions of ICT capability. Finally, ANOVA was used to find differences between different age and size groups.

Table 2 Thirteen aspects of ICT capability

\begin{tabular}{ll}
\hline ICT1 EXISTINGCOL & Maintaining collaboration with existing business partners \\
ICT2 NEWCOL & Establishing business collaboration with new partners \\
ICT3 INTCOMM & Handling communication within the firms (e.g., intranet) \\
ICT4 EXTCOMM & Handling external communication with the firm's stakeholders \\
& (e.g., extranet) \\
ICT5 ACCESSINFO & Accessing information (e.g., market, customers) \\
ICT6 STRATPLAN & Enabling strategic planning \\
ICT7 COSTSAVE & Enabling cost savings \\
ICT8 GLOBALBUS & Enabling global business with partners far away \\
ICT9 COMPDEV & Enabling competence/skills development for employees \\
ICT10 WORKFLEX & Enabling work flexibility (e.g., work outside the office) \\
ICT11 PRODEVELOP & Enabling the product development process \\
ICT12 SERVQUAL & Enabling better customer service quality \\
ICT13 MARKACTIVTY & Promoting marketing activities \\
\hline
\end{tabular}

Source: Adapted from Johannessen et al. (1999)

\section{Results}

Factor analysis was used to recognise and categorise different dimensions within the 13 ICT usages. Three dimensions were: ICT use for internal purposes, ICT use for communication, and ICT use for collaboration. Table 3 illustrates the loadings for each item, where the loadings lower than 0.30 have been suppressed. At the bottom of the table, the main characteristics associated with these dimensions are stated. Three usages associated with ICT capabilities were excluded as they did not explicitly relate to any particular dimension, and are reported in italics in Table 3 (ICT 8, ICT11, and ICT12). We, thus, ended up with four categories of internal use of ICT $(\alpha=0.75)$, three usages of ICT for communication $(\alpha=0.78)$ and three usages of ICT for collaboration $(\alpha=0.64)$. The reliability check for these dimensions revealed Cronbach's alpha $(\alpha)$ coefficients well above 0.5 , which are the cut-off level for exploratory research. It is only ICTs for collaboration that do not reach the desired 0.7 level for confirmatory studies (Nunally, 1978). Thus, the reliability is more than satisfactory. 
To investigate the level of ICT capability possessed by technology-based small firms, the mean value for all 13 types of utilisation are illustrated in Figure 1 and the mean value of the three dimensions of ICT capability are illustrated in Figure 2. The figures show that technology-based small firms, overall, have a high level of ICT capability. However, from the 13 different uses of ICT capabilities, five were extensively used by small firms, namely: work flexibility (ICT10), accessing information (ICT5), maintaining collaboration with business partners (ICT1), customer service quality (ICT12), and internal communication (ICT3). On the scale from 0 to 6 , these usages were all rated above four and are marked in black in Figure 1. Regarding the ICT capability dimensions, ICT use for collaboration was the highest at 4.35 , whereas the other two dimensions were at a similar level (3.82 and 3.85). This shows the heavy reliance of small firms on ICT for collaborating with new and existing business partners.

Table 3 The main groups for addressing ICT capability

\begin{tabular}{|c|c|c|c|}
\hline & $\begin{array}{c}\text { Internal use } \\
\text { of ICT }\end{array}$ & $\begin{array}{l}\text { ICT use for } \\
\text { communication }\end{array}$ & $\begin{array}{l}\text { ICT use for } \\
\text { collaboration }\end{array}$ \\
\hline ICT1 EXISTINGCOL & & & 0.84 \\
\hline ICT2 NEWCOL & & & 0.78 \\
\hline ICT3 INTCOMM & & 0.66 & \\
\hline ICT4 EXTCOMM & & 0.82 & \\
\hline ICT5 ACCESSINFO & 0.69 & & \\
\hline ICT6 STRATPLAN & 0.79 & & \\
\hline ICT7 COSTSAVE & 0.69 & & \\
\hline \multicolumn{4}{|l|}{ ICT8 GLOBALBUS } \\
\hline ICT9 COMPDEV & 0.62 & & \\
\hline ICT10 WORKFLEX & & & 0.63 \\
\hline \multicolumn{4}{|l|}{ ICT11 PRODEVELOP } \\
\hline \multicolumn{4}{|l|}{ ICT12 SERVQUAL } \\
\hline ICT13 MARKACTIVTY & & 0.57 & \\
\hline Cronbach alpha $(\alpha)$ & 0.75 & 0.78 & 0.64 \\
\hline Main characteristics & $\begin{array}{l}\text { Internal use of ICT } \\
\text { refers to those firm } \\
\text { activities which are } \\
\text { closely related to } \\
\text { achieving internal } \\
\text { efficiency }\end{array}$ & $\begin{array}{l}\text { ICT use for } \\
\text { communication } \\
\text { refers to a better flow } \\
\text { of information inside } \\
\text { and outside the firm }\end{array}$ & $\begin{array}{l}\text { ICT use for } \\
\text { collaboration addresses } \\
\text { maintaining and } \\
\text { establishing new } \\
\text { relationships with } \\
\text { different actors }\end{array}$ \\
\hline
\end{tabular}

ANOVA tests were performed to examine the difference between the age and size groups. Three age groups were formed, consisting of 59 young firms ( $0-5$ years), 99 middle-aged firms (6-10 years), and 133 old firms ( 10 years and more). The analysis shows no significant differences regarding age, indicating similar usages independent of firm age. The two groups that were created for firm size consisted of 116 micro firms (0-9 employees) and 175 small firms (10-50 employees). Here, substantial differences were identified. Figure 3 shows the mean values for both these groups in terms of ICT 
capability dimensions. Clearly, the larger firms have higher levels of ICT usage for all three dimensions. In particular, ICT used for collaboration, and the internal use of ICT, is substantially higher in the group with larger firms. A more detailed report of the results is shown in Figure 4, where only those usages are shown that were significantly different according to the ANOVA test. Overall, the usage of ICT was higher for small firms as compared with micro firms; in particular, internal communication (ICT3) and marketing activity (ICT13) are considerably higher for the larger firms.

Figure 1 Mean value for 13 aspects of ICT capability

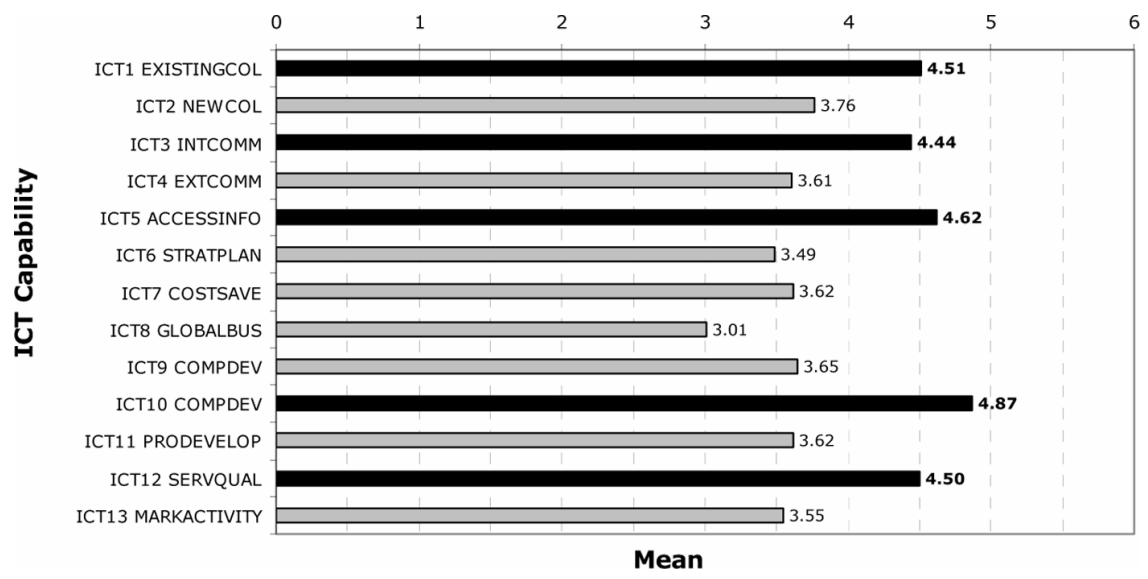

Figure 2 Mean values for ICT capability dimensions

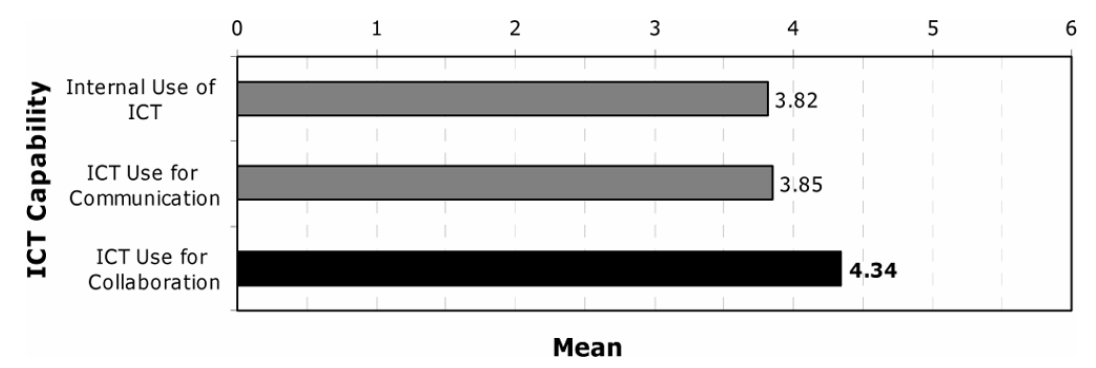

Figure 3 Mean value for micro and small firms' ICT dimensions

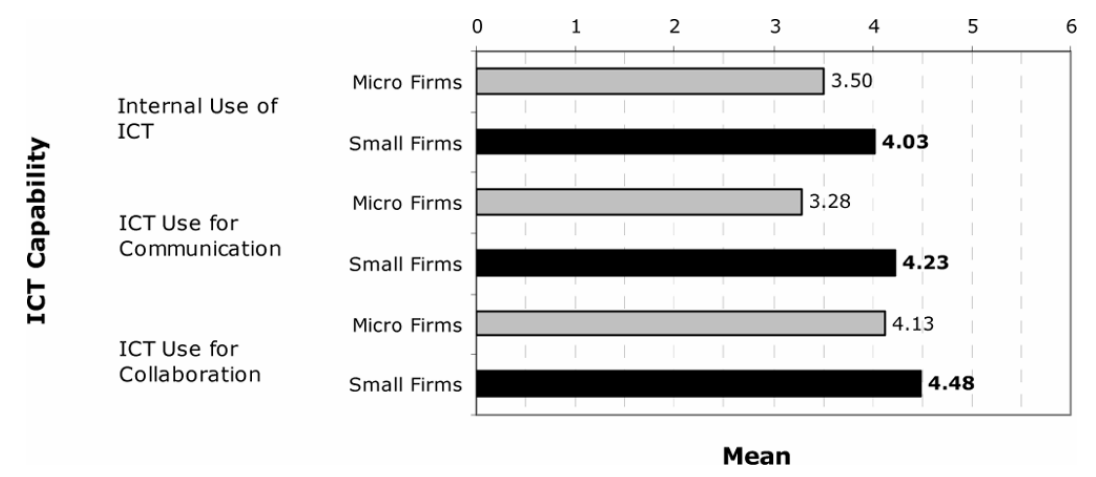


Figure 4 Mean value for micro and small firms' ICT usages

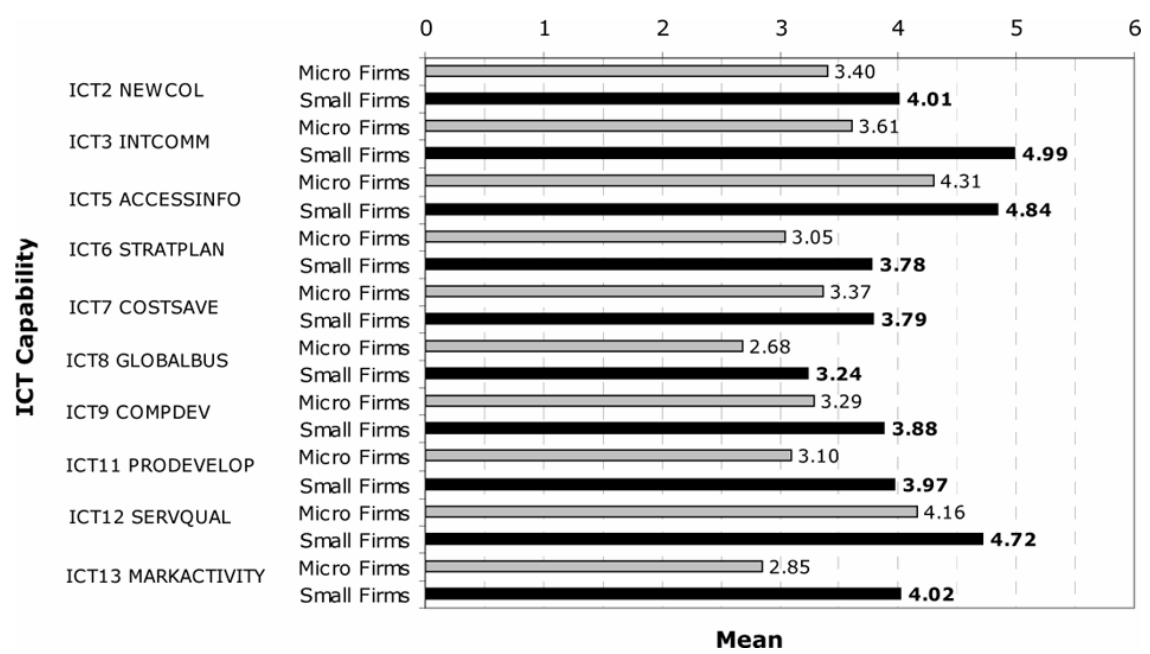

\subsection{Post hoc analysis}

To investigate further the difference in firm size groups, we carried out a set of post-hoc analyses. This helped to shed light on the previous result that shows that micro firms have lower levels of ICT capability. Using a $K$-mean cluster analysis where the three dimensions of ICT use were used for clustering, we split the sample into two groups (where one was high users, and the other low users, of ICT). By maintaining the size groups, we now had four groups or clusters. These clusters consisted of 55 micro firms with low ICT capability, 60 micro firms with high ICT capability, 50 small firms with low ICT capability, and 124 small firms with high ICT capability (see Table 4). As each cluster had a substantial number of firms in it, this demonstrated the existence of both high and low ICT users in the two firm size groups. However, there was a higher percentage of high users in the group containing larger firms $(71 \%$ as compared with $52 \%$ ). The mean value for the clusters in relation to ICT capability dimensions indicated that high/low ICT users in both micro and small firms were similar (not significantly different at a 0.05 level using Tukey's HSD test) when we look at the internal use of ICT and ICT use for collaboration. However, for ICT use for communication, micro firms with low ICT use were significantly lower in use compared with small firms with low ICT use. Among high ICT users, the levels of usage are not significantly different from each other.

Table 4 Cluster analysis of firm size group's ICT capability dimensions

\begin{tabular}{lcccccc}
\hline & \multicolumn{2}{c}{ Micro firms } & & \multicolumn{2}{c}{ Small firms } \\
\cline { 2 - 3 } \cline { 5 - 6 } & $\begin{array}{c}\text { Low ICT } \\
(N=55)\end{array}$ & $\begin{array}{c}\text { High ICT } \\
(N=60)\end{array}$ & & $\begin{array}{c}\text { Low ICT } \\
(N=50)\end{array}$ & $\begin{array}{c}\text { High ICT } \\
(N=124)\end{array}$ \\
\hline Internal use of ICT & 2.49 & & 4.42 & & 2.78 & 4.54 \\
ICT use for communication & 2.18 & & & & & \\
ICT use for collaboration & 3.21 & 4.71 & & & 3.05 & 4.71 \\
\hline
\end{tabular}




\section{Discussion, conclusions, and implications}

\subsection{Discussion}

In this section, we will discuss the main finding under three themes based on this study's research questions:

- the level of ICT capability possessed by Swedish technology-based small firms

- the purposes for which ICT capability is used by technology-based small firms

- the extent to which ICT capability is related to firm age and size.

The level of ICT capability is mapped using the 13 application areas given in Table 2. Each ICT use was carefully selected based on a literature review and on input from the explorative case studies. Many previous studies have highlighted the problems faced by small firms in using ICT (see e.g., Southern and Tilley, 2000). However, in the context of technology-based small firms, this does not seem to hold true. Our results, instead, clearly show that small hi-tech firms currently have quite a high ICT capability. On the scale from 0 to 6 , the minimum mean value was 3.01 and the highest 4.87. A similar trend was observed for the ICT capability dimensions we used in this study: internal use of ICT (3.82), ICT use for communication (3.85), and ICT use for collaboration (4.34). According to Johannessen et al. (1999), a reasonable explanation for this high level of ICT capability may be related to the degree of familiarity and maturity in using technology-based tools and technological standardisations in the specific group we have addressed in this study, resulting in a higher level of ICT capability compared with small firms in other industries.

The second theme refers to the main purposes for which ICT capability is used by technology-based small firms. From the 13 categories of utilisation, five have considerably high mean values. First, enabling work flexibility (ICT10) refers to ease of working from different locations and also having flexibility with working hours. This usage had the highest value, which reflects that for small firms it is vital that employees can work according to their needs and convenience. In many cases, the employees might not be fully employed and under these circumstances the role of ICT becomes important for enabling flexibility. The second usage refers to the use of ICT to access information (ICT5). Easy access to information is precious for firms operating in a dynamic environment, and firms need to be updated on new technology or innovations which might influence the firms' future competitiveness. The internet has become an essential enabler of information exchange and this role seems to be considerably important for small firms. Third, ICT12 deals with the use of ICT for better customer service. ICT has, for a long time, been regarded as a tool for providing customers with better services in terms of quicker responses and closer interactions. Certainly, customer relationship (CRM) solutions or other applications would be useful for achieving better service quality as customers' needs can be met effectively. The fourth and fifth usages deal with ICT use for maintaining relations with partners (ICT1) and achieving better internal communication (ICT3). Both of these hold high significance for small technology-based firms. With the help of an intranet, small firms can attain effective internal communication, which might make them operate closely and also facilitate closer relations with existing partners. Finally, in terms of ICT capability dimensions, ICT use for collaboration has the highest mean value. This is not surprising as small firms' ability 
to collaborate with different partners is argued to be an important source of achieving competitive advantage. Inter-firm collaboration enables small firms to gain access to different resources, enhance learning, and facilitate innovations (Pittaway et al., 2004; Powell et al., 1996). Thus, using ICT to achieve these objectives seems to be critical for small hi-tech firms.

Regarding the third theme, interesting differences regarding the extent to which ICT capability may be related to firm age and size were revealed. Our findings depict no differences related to firm age, indicating a similar ICT usage independent of firm age. There are several possible interpretations of this specific result. One is that being operative in a dynamic, and often turbulent, hi-tech environment requires companies that are updated, implying that firms with more than ten years of experience have 'learned the ropes' in order to survive. Another interpretation is that here we address overall quite young firms in hi-tech sectors and not family businesses inherited from previous generations, and that also addressing small firms in more mature branches of industry would probably have generated other results. It may, moreover, be suggested that firm age in this specific respect is less interesting compared with the age and experience of the firm owner or management team. On the other hand, our results depict significant differences related to firm size. Particularly, two forms of ICT utilisation were found to relate to the size of the firm. First and less surprising, a higher degree of utilisation of internal communication (ICT3) in small, as compared with micro firms, may be explained by the number of in-house communication nodes per se and the need for a more developed structure for communication that more employees require. Second, the finding that micro firms, to a lesser degree, use ICT for promoting marketing activities (ICT13) might, at first glance, seem surprising, since these small firms should be the ones that have the most to gain from compensating for their smallness by a more extensive utilisation of ICT. A possible interpretation of this result is that these small hi-tech companies often target niche markets where trading and interaction with customers are driven by personal contacts and relations. For firms with more employees, the market might stretch out to global partners and due to these conditions the utilisation of distance-spanning and cost-effective ICT solutions for communication increases. However, post-hoc analyses showed that firm size groups are not entirely distributed into two groups since, within both small and micro firms, there are low and high ICT users and that they have differences in relation to ICT capability dimensions. Based on the cluster analysis (Table 4), we can see that high and low uses of ICT were similar regardless of firm size. This can be related to our explorative case study, where the micro firm had a higher ICT capability than both the smaller firms. It was also clear that the high ICT capability was instrumental for the micro firm to operate. Thus, it can be argued that high levels of ICT capability can also exist (and be highly beneficial) in micro firms. However, the proportion of high users is substantially lower among micro firms, indicating that a micro firm can operate more easily without a high level of ICT capability. This seems to be most true for the communication dimension. Since a micro firm can handle communication quite well with informal tools, ICT for communication may not be so important when the firm only consists of a limited numbers of employees.

\subsection{Conclusions}

The title of this paper raises the question of how small firms use ICT for business purposes. This was further narrowed down to technology-based small firms due to their 
important role in the national economy. Our results suggest that technology-based firms may be regarded as front-runners in terms of ICT capability. From the 13 different ICT applications investigated here, almost all were ranked above average. Three clear dimensions were identified: ICT use for internal purposes, ICT use for communication, and ICT use for collaboration. The analysis showed that ICT use for collaboration seems to be a specific characteristic of these firms. In addition, firm age does not seem to have any significant effect on the level of ICT capability, whereas for firm size there are significant differences in the utilisation of ICT since micro firms were marginally lower in using ICT compared to smaller firms.

\subsection{Implications for theory and practice}

This study has aimed to develop our understanding of the concept of ICT capability and, by building on previous research in the field and data from both explorative case studies and more robust quantitative data, has tried to conceptualise and empirically test aspects and dimensions related to this concept. We believe that our findings will stimulate further research in this specific field, where several interesting tracks for future research can be identified. First, RBV argues that firms with unique capabilities, such as ICT capability, are able to achieve competitive advantage. According to Santhanam and Hartono (2003, p.151), "to continue the assessment of the impact of IT capability, it is critical to develop standardised scales to measure firm's level of? IT capability". Although extensively addressed in previous research, only a few studies have explored this proposition. In addition, these studies have mainly focused on large or medium-sized enterprises (Bharadwaj, 2000; Bhatt and Grover, 2005; Ravichandran and Lertwongsatien, 2005). Thus, this study may be regarded as an initial step towards developing a RBV-based approach on ICT capability with a specific focus on small and micro firms. We encourage other researches to build on this study and use the ICT capability measurements in relation to performance outcomes (e.g., growth).

Second, it should be noted that the empirical findings of this study emanate from one specific small firm sector (hi-tech small firms). To replicate this study in other settings is an avenue for further research, since the results from another industrial setting may be expected to be different and these differences can be appealing for further investigation. Third, the main empirical evidence from this study is drawn from a snap-shop survey study. It would also be interesting to study the phenomenon from a more dynamic perspective, where e.g., longitudinal studies of how ICT capabilities evolve over time should be of utmost interest. All these prospective tracks should be helpful in further building this specific research field and providing answers that are lacking in this current study.

The main practical contribution of this study is towards providing a condensed picture of a complicated phenomenon for small firm managers and policy makers, pinpointing e.g., the variety of ICT application areas involved and the different dimensions of ICT capability. This may serve as a base for reflection and self-evaluation on the topic of how ICT and ICT capabilities may be developed in order to support the further development of small hi-tech companies. 


\section{References}

Acar, E., Kocak, I., Sey, Y. and Arditi, D. (2005) 'Use of information and communication technologies by small and medium-sized enterprises (SMEs) in building construction', Construction Management and Economics, Vol. 23, No. 7, pp.713-722.

Barney, J.B. (1991) 'Firm resources and sustained competitive advantage', Journal of Management, Vol. 17, No. 1, pp.99-120.

Bharadwaj, A.S. (2000) 'A resource-based perspective on information technology capability and firm performance: an empirical investigation', MIS Quarterly, Vol. 24, No. 1, pp.169-196.

Bhatt, G.D. and Grover, V. (2005) 'Type of information technology capability and their role in competitive advantage: an empirical study', Journal of Management Information Systems, Vol. 22, No. 2, pp.253-277.

Caldeira, M.M. and Ward, J.M. (2003) 'Using resource-based theory to interpret the successful adoption and use of information systems and technology in manufacturing small and medium-sized enterprises', European Journal of Information Systems, Vol. 12, No. 2, pp.127-141.

Clemons, E.K. and Row, M.C. (1991) 'Sustaining IT advantage: the role of structural differences', MIS Quarterly, Vol. 15, No. 1, pp.275-292.

Cohen, W.M. and Levinthal, D.A. (1990) 'Absorptive capacity: a new perspective on learning and innovation', Administrative Science Quarterly, Vol. 35, No. 1, pp.128-152.

Delmar, F., Davidsson, P. and Gartner, W.B. (2003) 'Arriving at the high-growth firm', Journal of Business Venturing, Vol. 18, No. 2, pp.189-216.

Fillis, I., Johansson, U. and Wagner. B. (2003) 'A conceptualisation of the opportunities and barriers to e-business development in the smaller firm', Journal of Small Business and Enterprise Development, Vol. 10, No. 3, pp.336-344.

Flamholtz, E. and Randle, Y. (2000) Growing Pains: Transitioning from an Entrepreneurship to a Professionally Managed Firm, Jossey-Bass, San Francisco, CA.

Greiner, L.E. (1972) 'Evolution and revolution as organizations grow', Harvard Business Review, Vol. 50, No. 4, pp.37-46.

Hultman, J. and Eriksson, L.T. (2008) 'The balancing acts in SME e-commerce development: a multiple case study', International Journal of Electronic Business, Vol. 6, No. 5, pp.476-497.

Jarvenpaa, S.L. and Leidner, D.E. (1998) 'An information company in Mexico: extending the resource-based view of the firm to a developing country context', Information System Research, Vol. 9, No. 4, pp.342-361.

Johannessen, J-A., Olaisen, J. and Olsen, B. (1999) 'Strategic use of information technology for increased innovation and performance', Information Management and Computer Security, Vol. 7, No. 1, pp.5-22.

Johansson, D. (2004) 'Is small beautiful? The case of the Swedish IT industry', Entrepreneurship and Regional Development, Vol. 16, No. 4, pp.271-287.

Levy, M., Powell, P. and Yetton, P. (2001) 'SMEs: aligning IS and the strategic context', Journal of Information Technology, Vol. 16, No. 3, pp.133-144.

Martin, L. and Matlay, H. (2001) 'Blanket approaches to promoting ICT in small firms: some lessons from the DTI ladder adoption model in the UK', Internet Research, Vol. 11, No. 5, pp.399-410.

Mata, F.J., Fuerst, W.L. and Barney, J.B. (1995) 'Information technology and sustained competitive advantage: a resource-based analysis', MIS Quarterly, Vol. 19, No. 1, pp.487-505.

Matlay, H. and Addis, M. (2003) 'Adoption of ICT and e-commerce in small businesses: an HEI-based consultancy perspective', Journal of Small Business and Enterprise Development, Vol. 10, No. 3, pp.321-335. 
Miller, D. (1991) 'Stale in the saddle: CEO tenure and the match between organization and environment', Management Science, Vol. 37, No. 1, pp.34-52.

Nieto, M.J. and Fernandez, Z. (2006) 'The role of information technology in corporate strategy of small and medium enterprises', Journal of International Entrepreneurship, Vol. 3, No. 4, pp.251-262.

Nunally, J.C. (1978) Psychometric Theory, McGraw-Hill, New York.

Parida, V. and Westerberg, M. (2006) 'ICT use for innovation in Swedish industrial service SMEs', Proceedings of the First Nordic Innovation Research Conference - Finnkampen, Oulu, Finland, pp.167-180.

Pittaway, L., Robertos, M., Munir, K., Denyer, D. and Neely, A. (2004) 'Networking and innovation: a systematic review of the evidence', International Journal of Management Reviews, Vol. 5, No. 6, pp.137-168.

Porter, M.E. (2001) 'Strategy and the internet', Harvard Business Review, March, pp.63-78.

Powell, T.C. and Dent-Micallef, A. (1997) 'Information technology as competitive advantage: the role of human, business, and technology resources', Strategic Management Journal, Vol. 18, No. 5, pp.375-405.

Powell, W.W., Koput, K.W. and Smith-Doerr, L. (1996) 'Interorganizational collaboration and the locus of innovation: networks of learning in biotechnology', Administrative Science Quarterly, Vol. 41, No. 1, pp.116-145.

Quayle, M. (2003) 'E-business in a turbulent world: usage in European small and medium size enterprise', International Journal of Electronic Business, Vol. 1, No. 1, pp.41-52.

Ravichandran, A. and Lertwongsatien, C. (2005) 'Effect of information system resources and capabilities on firm performance: a resource-based perspective', Journal of Management Information System, Vol. 21, No. 4, pp.237-276.

Ruiz-Mercader, J., Merono-Cerdan, A.L. and Sabater-Sanchez, R. (2006) 'Information technology and learning: their relationship and impact on organisational performance in small businesses', International Journal of Information Management, Vol. 26, No. 1, pp.16-29.

Santhanam, R. and Hartono, E. (2003) 'Issues in linking information technology capability to firm performance', MIS Quarterly, Vol. 27, No. 1, pp.125-153.

Southern, A. and Tilley, F. (2000) 'Small firms and Information and Communication Technologies (ICTs): toward a typology of ICTs usage', New Technology, Work, and Employment, Vol. 15, No. 2, pp.138-154.

Taylor, M. and Murphy, A. (2004) 'SMEs and e-business', Journal of Small Business and Enterprise Development, Vol. 11, No. 3, pp.280-289.

Thomke, S.H., von Hippel, E. and Franke, R. (1998) 'Models of experimentation: an innovative process - and competitive - variable', Research Policy, Vol. 27, No. 3, pp.315-332.

Venkatraman, N. (1994) 'IT-enabled business transformation: from automation to business scope redefinition', Sloan Management Review, Vol. 35, No. 2, pp.73-88.

Wade, M., Johnston, D. and McClean, R. (2004) 'Exploring the net impact of internet business solution adoption on SME performance', International Journal of Electronic Business, Vol. 2, No. 4, pp.336-350.

Zaheer, A. and Venkatraman, N. (1994) 'Determinants of electronic integration in the insurance industry: an empirical test', Management Science, Vol. 40, No. 5, pp.549-566. 